\title{
An Anaphylactic Reaction to Highly Purified Pork Insulin. Confirmation by RAST and RAST Inhibition
}

\author{
C. Carini ${ }^{1}$, J. Brostoff ${ }^{1}$ and A. B. Kurtz ${ }^{2}$ \\ ${ }^{1}$ Department of Immunology and ${ }^{2}$ The Cobbold Laboratories, Middlesex Hospital Medical School, London, UK
}

\begin{abstract}
Summary. We describe a patient who had an anaphylactic reaction to highly purified pork insulin; he was not allergic however to beef insulin. The sensitivity to pork but not to beef insulin was confirmed by skin testing, radioallergosorbent test (RAST) and RAST inhibition. A scheme is suggested for the investigation of such patients.
\end{abstract}

Key words: Anaphylaxis, radioallergosorbent test, highly purified insulin, beef insulin, allergen.

There have been reports of anaphylactic reactions to insulin, the first being by Williams [1], who described a patient who was allergic to insulin extracted from pork pancreas but not to a beef extract. At that time insulin was very impure and it is likely that the allergen was not insulin. It has always been difficult to prove the precise nature of the allergen causing such reactions and with increasing purity of insulin preparations allergic reactions have become increasingly rare. Patients have been described who had allergic reactions to conventional insulins [2,4]. There have also been instances of reactions to highly purified insulins [5, 12], but with one doubtful exception all patients had received conventional insulins previously [12]. We describe a patient who became allergic to highly purified pork, but not to beef insulin, in whom we have demonstrated by skin testing and RAST that the insulin is the allergen and that the immunopathological mechanism was IgE mediated.

\section{Patient and Methods}

The patient is an Australian male born in 1953. During childhood, he experienced episodes of allergic rhinitis, there being no family history of atopy. Diabetes mellitus was diagnosed in 1968 and treatment with insulin started. Initially he received beef protamine zinc and soluble insulins. After 2 years of treatment, his insulin requirement had increased to more than 200 units daily. Treatment was then changed to Actrapid (pork) and Rapitard (pork 25\%/beef $75 \%$ ) insulins (Novo Industri, Denmark) with a reduction in his insulin requirement. He has been seen regularly in our diabetic clinic since 1977 and his diabetes has been well controlled on an average dose of $90 \mathrm{U}$ insulin/day (weight: $80 \mathrm{~kg}$ ) and there have been no complications of the disease.
In May 1980, a change was made in his insulin regimen. Mixtard insulin $(52 \mathrm{U})$, a highly purified pork insulin (30\% neutral / $70 \% \mathrm{NPH}$; Nordisk Denmark), was substituted for the Rapitard insulin, of which he had been taking $72 \mathrm{U}$ daily. After 1 week, wheals started to appear at injection sites and 2 weeks later a generalised reaction occurred. This reaction started within seconds of an insulin injection. The patient experienced difficulty in breathing with chest tightness and laryngeal obstruction and he developed a generalised urticarial eruption i.e. anaphylaxis. While on the Actrapid and Mixtard insulins diabetic control had been good. After the anaphylactic reaction, the patient resumed his previous insulin regimen and has subsequently been entirely free of allergic symptoms.

Prick testing was performed using normal saline, insulin vehicle, and pork and beef insulins (both highly purified and conventional preparations) at a concentration of $40 \mathrm{U} / \mathrm{ml}$. Pork and beef extracts (Bencards, Brentford, UK), histamine (1\%) as a positive control and saline were also used. The tests were performed on the volar aspect of the forearm and were read at $20 \mathrm{~min}$. A positive test was a wheal at least twice the size of the saline control.

Intradermal tests were also performed by injecting $0.05 \mathrm{ml}$ of various solutions including a diluent control. The insulin test dose was initially $0.002 \mathrm{U}$ with subsequent doses increasing tenfold to 2 U. A positive reaction was judged in the same way as with the prick testing and the area of the wheal was measured by planimetry.

Goat anti-human IgE was supplied by the Rheumatic Diseases Laboratory, Maine Medical Center, Portland, Oregon, USA.

Iodination of the antiserum was performed by the chloramine $T$ method of Hunter and Greenwood [13] using ${ }^{125}$ Iodine. The iodinated antiglobuin was diluted in phosphate buffer $(0.04 \mathrm{~mol} / \mathrm{l}), \mathrm{pH}$ 7.4 , containing sodium choride $0.15 \mathrm{~mol} / \mathrm{I}$ (PBS) and $1 \%$ Tween 20 , to give 100,000 counts. $100 \mathrm{~s}^{-1} \cdot 100 \mu^{-1}$, specific activity $1.49 \times 10^{8}$ $\mathrm{Ci} / \mathrm{mol}$.

Discs of Whatman 54 paper $3 \mathrm{~mm}$ in diameter were prepared with a paper punch and activated using cyanogen bromide [14]. The discs were sensitized with purified pork or purified beef insulin $(10 \mu \mathrm{g} / \mathrm{ml})$, diluted in sodium bicarbonate $(0.1 \mathrm{~mol} / 1)$ and incubated for $4 \mathrm{~h}$ at $4{ }^{\circ} \mathrm{C}$ on a rocking platform.

The discs were then washed once in $200 \mathrm{ml}$ of sodium bicarbonate $(0.1 \mathrm{~mol} / \mathrm{l})$ and unreacted sites were blocked by incubation in $50 \mathrm{mmol} / 1$ ethanolamine $200 \mathrm{ml}$ diluted in sodium bicarbonate $0.1 \mathrm{~mol} / 1$ for $1 \mathrm{~h}$ at $4{ }^{\circ} \mathrm{C}$. The discs were then washed in sodium bicarbonate $0.1 \mathrm{~mol} / \mathrm{l}$ and then in PBS and stored at $-20^{\circ} \mathrm{C}$.

The binding of ${ }^{125} \mathrm{I}$ labelled insulin by sera was determined using a $15 \%$ polyethylene glycol separation [15]. This method determines the binding of insulin by IgG.

\section{The Radioallergosorbent Test (RAST)}

This test was performed according to the method of Wide et al. [14], using discs sensitized with highly purified beef or pork insulin. Control sera were obtained from insulin treated diabetic subjects. Two control groups were studied, one with IgG insulin binding of 

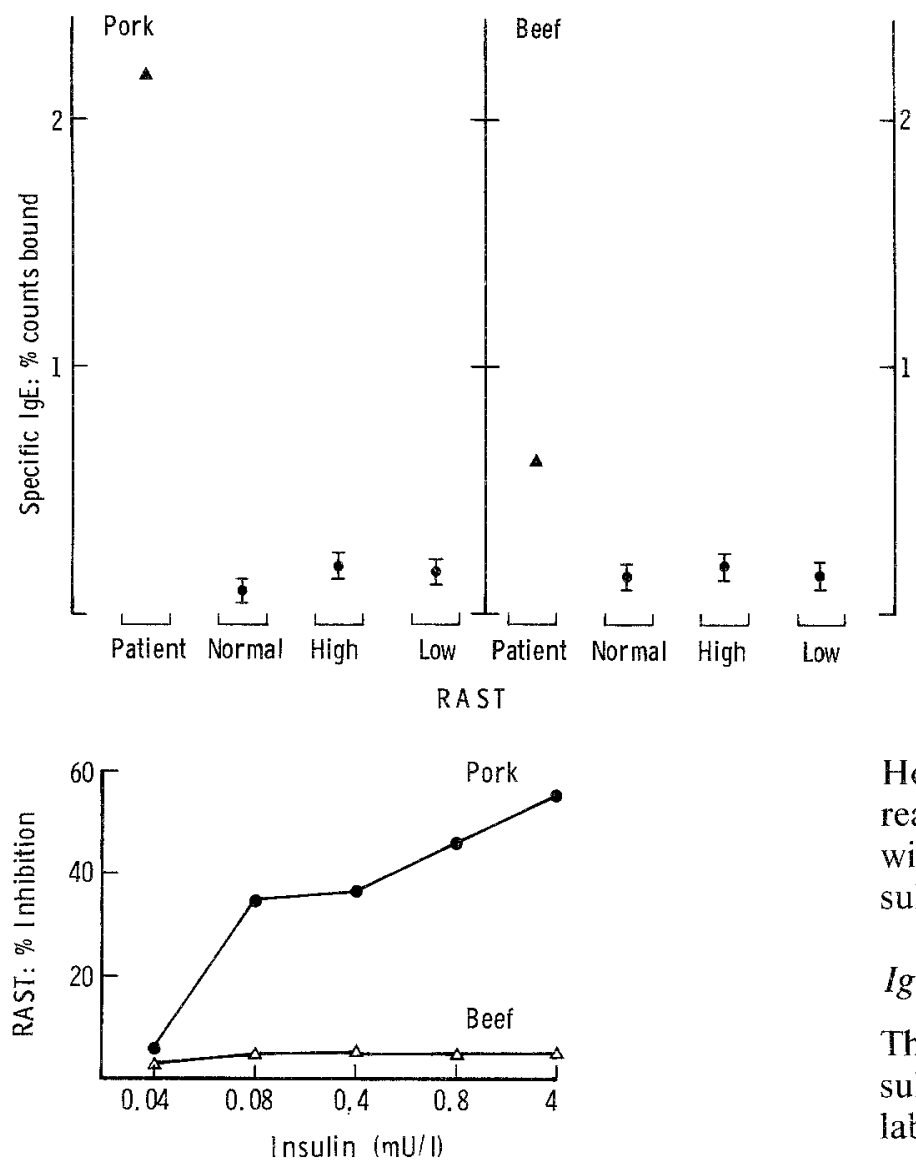

Fig. 2. RAST inhibition by pork and beef insulin. Patient's serum was incubated with different concentrations of pork $(\bullet-)$ ) and beef insulin $(\Delta-\Delta)$ and then tested with discs sensitized with pork insulin. Inhibition is clearly seen when serum is incubated with pork insulin but not beef, thus showing the specificity

less than $3 \%$ and the other with binding of $20 \%-40 \%$, the first group having very low or undetectable insulin binding and the second having moderately high binding without insulin resistance.

\section{RAST Inhibition}

To test the specificity of the IgE anti-pork insulin antibody, an inhibition RAST was set up as follows: pork or beef insulin at concentrations between $0-4 \mathrm{mU} / \mathrm{ml}$ was added to the patient's serum, which was then assayed on a pork insulin sensitized disc to show inhibition of the binding of ${ }^{125} I$ anti-human IgE to the discs.

\section{Results}

Skin tests were first performed 4 weeks after the anaphylactic reaction. Positive skin prick tests were obtained with the pork insulins (Actrapid, Leo Neutral and Mixtard insulins) but no responses were seen with beef insulins (Actrapid beef, Wellcome soluble and Wellcome NPH insulins), other allergens or diluent control. Rapitard insulin, which contains both beef and pork insulins, also gave a positive reaction. After a further 7 months, skin prick tests were repeated and were negative for both pork and beef insulins.
Fig. 1. IgE antibodies (RAST) to insulin in diabetic and normal subjects. The patient $(\boldsymbol{\Lambda})$ showed high specific binding of $\operatorname{IgE}$ to pork discs. Other diabetic patients with high $(n=25)$ and low ( $n=25)$ IgG insulin binding are included. Results for the group are given as mean \pm SEM

However, following intradermal challenge, a positive reaction was seen with $2 \mathrm{U}$ pork insulin (Actrapid) with negative reactions to lower doses and to beef insulin (Actrapid beef).

\section{IgG Antibodies}

The patient's serum showed only a modest level of insulin binding; $18 \%$ of labelled beef insulin and $12 \%$ of labelled pork insulin were bound.

\section{IgE Antibodies}

When the patient's serum was tested by RAST using pork insulin sensitized discs, a positive response was seen while a weakly positive response was shown using beef insulin sensitized discs. None of the diabetic control subjects had allergic symptoms and none showed any $\operatorname{IgE}$ antibodies directed to either pork or beef insulin (Fig. 1).

RAST inhibition showed that the binding of the IgE to the pork insulin sensitized discs could be inhibited by pork insulin but not by beef insulin in equivalent concentrations (Fig. 2), thus confirming the clinical history, skin tests and RAST.

\section{Discussion}

Insulin preparations can be immunogenic and immunoglobulins of all classes can be induced in patients during treatment [16]. The immunogenicity appears to be related more to the physical characteristics of the insulin than to the species of origin [15]. Anaphylaxis is the most dangerous and dramatic immunlogical side effect of insulin treatment and is now very rare, most probably because currently used insulin preparations are less impure than they used to be. In patients treated with highly purified pork insulin, the induction of insulin binding $\mathrm{IgG}$ is much less than in 
patients treated with conventional beef insulin [15]. Lipoatrophy, which is thought to be an immunological phenomenon, is also less common. Type 1 allergic reactions to highly purified pork insulin have been described [5, 12]. In nearly all patients, primary immunization has been with conventional insulin as is the case with our patient. Marked species specificity, such as we observed in our patient, has not been described in those recent studies where insulin specific $\operatorname{IgE}$ has been documented.

We describe a patient who had a Type 1 anaphylactic reaction within seconds of the injection of a highly purified pork insulin. This reaction was typically that of an IgE mediated response. RAST, RASTinhibition and skin testing showed IgE directed to pork but not to beef insulin.

In this patient it is not clear what precisely triggered this immunological response; possibilities include the increase in the dose of pork insulin, the reduction in the dose of beef insulin or the change in insulin formulation. Urticaria to an isophane insulin but not to a zinc crystalline insulin of the same species was reported by Shore et al. [17]. They speculated that protamine, although not covalently bound to insulin, might render the insulin, as a hapten, antigenic. In our patient, initial 'immunisation' was with protamine zinc insulin and his allergic symptoms occurred with the re-introduction of a protamine containing insulin. If protamine did promote immunogenicity it is of interest that skin testing with beef protamine insulin was negative; unfortunately, we did not skin test him with protamine itself. After the anaphylactic reaction, our patient experienced no symptoms on resuming Actrapid and Rapitard insulins. This may be because of the lower dose of pork insulin, the presence of beef insulin or the absence of protamine.

The investigation of this patient followed classical clinical immunological lines and has allowed precise identification of the allergen. Skin prick tests, with intradermal tests if the skin-prick test are negative, RAST and RAST inhibition are a suitable battery of tests in such a clinical situation. RAST is a semiquantitative test, which does not appear to give false positive results in our hands, as insulin specific IgE was only detectable in our patient who had allergic symptoms and not in the insulin treated controls. There is, however, the theoretical danger of false negative results if insulin binding globulin (IgG) blocks the insulin sensitized disc preventing the binding of IgE. This problem was discussed by Nakagawa and Nakayama [8] whose experiments show that it appeared to be of little importance. The method of detecting insulin specific IgE which Patterson et al. described [2] is not in principle different to the RAST technique, using a double antibody system rather than a solid phase. A quite different method reported by Kumar [3] uses a solid phase anti-IgE with detec- tion of bound insulin specific IgE with radiolabelled insulin. However, using this method, insulin specific IgE was detected in many subjects who had not experienced allergic reactions. RAST inhibition seems a satisfactory way of investigating species specificity, although it may not be an especially sensitive method in this respect [8].

\section{References}

1. Williams JR (1922) A clinical study of the effects of insulin in severe diabetes. J Metab Res 2: 729-731

2. Patterson R, Mellies CJ, Roberts M (1973) Immunologic reactions against insulin II. IgE anti insulin, insulin allergy and combined $\mathrm{IgE}$ and $\mathrm{IgG}$ immunologic insulin resistance. J Immunol 110: 1135-1145

3. Kumar D (1977) Anti-insulin IgE in diabetics. J Clin Endocrinol Metab 45: 1159-1164

4. Kumar D, Rosenquist RJ, Parameswaran V (1979) Insulin allergy. Reaginic antibodies to insulin and proinsulin. J Clin Metab $49: 252-254$

5. Leslie D (1977) Generalised allergic reaction to monocomponent insulin. Br Med J 2: 736-737

6. Goldman RA, Lewis AE, Rose LI (1976) Anaphylactoid reaction to single component pork insulin. J Am Med Assoc 236: 1148-1149

7. Reisner C, Moul DJ, Cudworth AG (1978) Generalised urticaria precipitated by change to highly purified porcine insulin. Br Med J 2: 56-60

8. Nakagawa $S$, Nakayama H (1979) Immunogenicity of insulin with special reference to IgE antibody. In: Baba S, Kameko T, Yamaihara N (eds) Proinsulin, insulin, C peptide. Excerpta Medica, Amsterdam ICS 468: 170-173

9. Borsey DQ, Malone DNS (1979) Local cutaneous allergy to monocomponent insulin. Postgrad Med J 55: 199-200

10. Goldman JM, Brynildsen HC (1980) Generalised allergy to porcine and bovine monocomponent insulins. Br Med J 2: 1494-1497

11. Simmonds JP, Russell GI, Cowley AT, Sewell HF, Hearnshaw JR (1980) Generalised allergy to porcine and bovine monocomponent insulin. Br Med J 281 : 355-356

12. Schernthaner G, Ludwig H, Jarish R, Bruneder H (1981) Immediate-type allergy against insulin itself: clinical and immunological studies on a diabetic patient with insulin intolerance. Diabetes Care 4: 196-201

13. Hunter WM, Greenwood FC (1962) Preparation of iodine 131 labelled human growth hormone of high specific activity. $\mathrm{Na}-$ ture 194:495-497

14. Wide L, Bennich H, Johansson SGO (1967) Diagnoses of allergy by an in vitro test for allergic antibodies. Lancet 2:1105-1107

15. Kurtz AB, Nabarro JDN (1980) Circulating insulin binding antibodies. Diabetologia 19:329-334

16. Hamilton RG, Rendell M, Adkinson NF (1980) Serological analysis of human IgG and IgE anti-insulin antibodies by solid phase radio-immuno assays. J Lab Clin Med 96: 1022-1024

17. Shore RN, Shelley WB, Kyle GC (1975) Chronic urticaria from isophane insulin therapy: sensitivity associated with non-insulin components in commercial preparations. Arch Dermatol 111:94-97

Received: 5 June 1981

and in revised form: 18 January 1982

Dr. J. Brostoff

Department of Immunology

Arthur Stanley House

Middlesex Hospital Medical School

40-50 Tottenham Street

London W1P 9PG, UK 